\title{
REGULAÇÃO DA PESQUISA EM EDUCAÇÃO: TENSÕES ENTRE AUTONOMIA ÉTICA E HETERONOMIA NORMATIVA*
}

\author{
Pedro Savi $\mathrm{Neto}^{1}$ (1) \\ Mónica de La Fare ${ }^{2}$ (D)
}

\begin{abstract}
RESUMO: Este artigo tem como objetivo analisar o tema da regulação da conduta em pesquisa, passados mais de dois anos da vigência da Resoluçáo do Conselho Nacional de Saúde (CNS) no 510/2016. São investigadas três perspectivas (formativa, filosófica e normativa) para verificar as possibilidades de autonomia ética na pesquisa em contraposição à heteronomia normativa, especialmente no campo educacional, como parte das Ciências Humanas, Sociais e Sociais Aplicadas (CHSSA). A análise tem como principal base teórica a obra de Theodor W. Adorno e é realizada especialmente com base em uma das questóes motivadoras da Teoria Crítica da Sociedade, qual seja, a possibilidade de emancipação (autonomia) do indivíduo na sociedade administrada.
\end{abstract}

Palavras-chave: Ética. Pesquisa. Regulação. Educação.

\section{REGULATION OF RESEARCH IN EDUCATION: THE TENSIONS BETWEEN ETHICAL AUTONOMY AND NORMATIVE HETERONOMY}

ABSTRACT: This article aims at analyzing the issue of conduct regulation in academic research, with more than two years of the Resolution of the National Health Council (CNS) n. 510/2016. Three perspectives (formative, philosophical and normative) are investigated to verify the possibilities of ethical autonomy in research as opposed to normative heteronomy, especially in the educational field, as part of the Human, Social and Applied Social Sciences (CHSSA). The main theoretical basis of this analysis is the work of Theodor W. Adorno and it is carried out

\footnotetext{
*Este artigo é vinculado ao projeto de pesquisa $A$ regulação da ética e a formação na pesquisa em Educação do grupo de pesquisa Formação, ética e pesquisa em Educação, registrado no Conselho Nacional de Desenvolvimento Científico e Tecnológico (CNPq). O presente trabalho foi realizado com apoio da Coordenaçáo de Aperfeiçoamento de Pessoal Nível Superior - Brasil (CAPES) - Código de Financiamento 001, especificamente com bolsa do Programa Nacional de Pós-Doutorado para Pedro Savi Neto.

${ }^{1}$ Pontifícia Universidade Católica do Rio Grande do Sul, Escola de Humanidades, Programa de Pós-Graduação em Educação - Porto Alegre (RS), Brasil. E-mail: pedro.savi@pucrs.br

${ }^{2}$ Pontifícia Universidade Católica do Rio Grande do Sul, Escola de Humanidades, Programas de Pós-Graduação em Educação e em Serviço Social - Porto Alegre (RS), Brasil. E-mail: monica.fare@pucrs.br

DOI: 10.1590/ES0101-73302019191340
} 
especially from one of the motivating questions of the Critical Theory of Society: the possibility of emancipation (autonomy) of the individual in the administered society.

Keywords: Ethics. Research. Regulation. Education.

\title{
REGULACIÓN DE LA INVESTIGACIÓN EN EDUCACIÓN: TENSIONES ENTRE AUTONOMÍA ÉTICA Y HETERONOMÍA NORMATIVA
}

\begin{abstract}
RESUMEN: Este artículo tiene como objetivo analizar el tema de la regulación de la conducta en investigación, pasados más de dos años de la vigencia de la Resolución del Consejo Nacional de Salud (CNS) $n^{\circ}$ 510/2016. Serán investigadas tres perspectivas (formativa, filosófica y normativa) para verificar las posibilidades de autonomía ética en la investigación en contraposición a la heteronomía normativa, especialmente en el campo educacional, como parte de las Ciencias Humanas, Sociales y Sociales Aplicadas (CHSSA). El análisis tendrá como principal base teórica la obra de Theodor W. Adorno y será realizada especialmente a partir de una de las cuestiones motivadoras de la Teoría Crítica de la Sociedad, cual sea, la posibilidad de emancipación (autonomía) del individuo en la sociedad administrada.
\end{abstract}

Palabras clave: Ética. Investigación. Regulación. Educación.

\section{Considerações iniciais}

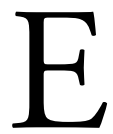

ste artigo tem como objetivo analisar o tema da regulação da conduta em pesquisa, passados mais de dois anos da vigência da Resolução do Conselho Nacional de Saúde (CNS) no 510, de 7 de abril de 2016 (BRASIL, 2016b), normativa nacional que estabeleceu a regulamentação específica para essas áreas do conhecimento. $\mathrm{O}$ argumento será desenvolvido a partir da (1) análise dos limites de possibilidade da liberdade necessária à formação da moralidade do sujeito na sociedade administrada ${ }^{1}$, avançará com a (2) investigação da desvalorização da atividade filosófica e será finalizado pela (3) problematização em torno da pressão social para a substituição da autonomia ética em pesquisa pela heteronomia normativa.

Em uma democracia, e esse regime político depende de sujeitos emancipados para seu verdadeiro funcionamento (ADORNO, 1995), a intervenção legislativa deveria ser, por princípio, subsidiária à esfera individual (DUARTE; NACLE, 2014) e aos valores socialmente construídos, aceitos e praticados. Contudo, a análise crítica permite concluir que, no âmbito da sociedade administrada, mecanismos de dominação social dificultam a emancipação ${ }^{2}$ do indivíduo, 
não favorecendo a formação da autonomia ética mediante o excesso de regulação sobre a atividade de pesquisa. Nesse contexto, a normatização passa a atuar como fonte artificial de princípios morais, substituindo o doloroso (mas necessário) processo de amadurecimento moral pela comodidade da regulação externa: as normas "significam uma heteronomia, um tornar-se dependente de mandamentos, de normas que não são assumidas pela razão própria do indivíduo" (ADORNO, 1995, p. 124). Isso se agrava em países com excessiva atividade legislativa, como é o caso do Brasil (OLIVEIRA, 2009), aumentando a dependência à norma e a confusão em torno do real significado da ética, além de aumentar as possibilidades de atravessamento normativo de áreas que despertam maior interesse econômico.

$\mathrm{Na}$ sociedade administrada, a atividade filosófica precípua de formular conceitos válidos, especialmente sobre aquilo que se entende por moralmente aceitável (SOUZA, 2003), resta intencionalmente prejudicada e é progressivamente substituída pela legislação e por meras opinióes não fundamentadas filosoficamente (FRANKFURT, 2005). No que concerne ao objeto central do presente artigo, a conduta em pesquisa nas Ciências Humanas, Sociais e Sociais Aplicadas (CHSSA) está regulamentada pelo CNS, entidade ligada ao Ministério da Saúde que normatizou a pesquisa nas CHSSA, em manifesto atravessamento normativo. A referida norma foi resultado de um conturbado processo legislativo, que não atendeu com o objetivo de respeitar as especificidades da pesquisa nessas áreas do conhecimento, conforme será tratado.

\section{Autonomia ética}

\section{Questão formativa}

A autonomia ética pressupóe, necessariamente, duas dimensões fundamentais e interdependentes: o próprio indivíduo e as possibilidades que a sociedade oferece para a formação da autonomia moral do indivíduo ${ }^{3}$, pois "não há emancipação possível sem a emancipação da sociedade" (ADORNO, 1993, p. 164). A possibilidade de emancipação na sociedade administrada é pensada por Adorno a partir da "pressão inimaginável exercida sobre as pessoas, seja simplesmente pela própria organização do mundo, seja num sentido mais amplo, pelo controle planificado até mesmo de toda realidade interior pela indústria cultural" (ADORNO, 1995, p. 181). Em Adorno, tal qual em Marx (FLECK, 2015), a crítica ao capitalismo é central ${ }^{4}$, contudo ela é complementada, de modo a oferecer ferramentas interpretativas atualizadas para analisar adequadamente as possibilidades de autonomia do sujeito no capitalismo tardio:

A crítica da economia política seguia sendo necessária para a teoria crítica, mas já não era mais suficiente, uma vez que agora é preciso também analisar o quanto a forma de racionalidade 
prevalecente está amalgamada com tal sistema; é preciso também criticar a dominação absoluta da natureza e pensar uma maneira de reconciliaçáo para com ela; por fim, ver como as próprias instâncias psíquicas dos indivíduos contribuem para a manutenção da dominação que paira sobre eles, assim como o processo de enfraquecimento da instância designada "eu" por Freud (FLECK, 2015, p. 91-92).

A complementação da crítica é necessária, pois, na nova fase do capitalismo vivida por Adorno, os mecanismos de dominação são escamoteados por uma aura de liberdade, ocultados por um tipo de racionalidade (instrumental). Mesmo não criando as condições necessárias para a emancipação, a sociedade burguesa utiliza formalmente conceitos relacionados com a possibilidade de emancipação justamente para fortalecer a dominação (como é o caso da saturação do termo ética - como se a falta de ética na sociedade pudesse ser compensada pela utilização exagerada do conceito, especialmente em normas). Essa contradição é originada no fato de que a lei de troca, elemento central para o desenvolvimento da sociedade burguesa, é contraditória ao desenvolvimento moral, supostamente pretendido por ela. Nessa medida, a sociedade administrada não oferece as condições necessárias à formação da moralidade, pois as açôes morais são, por definição, gratuitas (desvinculadas de contraprestação); enquanto a todo produto ou serviço corresponde uma contraprestação equivalente monetariamente (ADORNO, 1993, p. 32-33).

$\mathrm{Na}$ esteira do pensamento adorniano, Gruschka (2014) analisa a forma pela qual se projeta a contradição da sociedade burguesa sobre a escola, instância fundamental para a formação de um pesquisador comprometido com a ética na pesquisa. Segundo o educador alemão, a escola é determinada pelo contexto social e prepara para a sociedade competitiva por meio do fortalecimento da competição e das ferramentas necessárias para o êxito econômico. Justamente em função da mencionada contradição é que se faz possível compreender a razão pela qual a educação não se mostrou, ao longo da história da humanidade, capaz de cumprir integralmente com os objetivos de formar e libertar, pois "a moral da pedagogia está atrelada totalmente à imoralidade vigente nas estruturas da sociedade" (GRUSCHKA, 2014, p. 21).

Ou seja, as escolas (e as instituiçoóes educacionais em geral) estão estruturadas e organizadas de acordo com interesses econômicos, mas, formalmente, defendem uma formação baseada em valores humanos. Formalmente, pois "não tanto a aula - a transmissão de conhecimento, ou seja, a didática - educa, mas, sobretudo, a instituição escolar" (GRUSCHKA, 2014, p. 154). Se a estrutura é de controle e desconfiança, não é efetivo falar em liberdade, autonomia e confiança; se as atividades avaliativas conduzem a uma noção de competição e individualismo, não há efetividade ao falar em solidariedade e ética. 
Trata-se, conforme a análise de Gruschka (2014 e 2008), de uma espécie de imperativo econômico, com sofisticados mecanismos de integraçáo social, que se apropria da escola e induz a mediação estratégica de uma lógica própria e sistêmica. Nessa lógica funcional e calculista, conforme a dinâmica e as exigências do mercado, o conteúdo da formação e da ciência desloca-se sob a regência dos imperativos de consumo, isso exige a renúncia do conteúdo da formação cuja mediação pode ser observada inclusive na escola, por intermédio de sofisticados mecanismos de integração social, como a aula (GOMES, 2015, p. 152-153, grifo do autor).

Assim sendo, a principal instância de formação de um pesquisador é impregnada por uma lógica diversa daquela necessária para a formação da sua moralidade. O direito público à educação, um interesse do indivíduo e, sobretudo, da própria sociedade, é transformado em serviço, fazendo com que “jovens assumam as premissas do mercado como expectativa e sentido de suas próprias vidas" (GOERGEN, 2015, p. 12). Para transformar um direito social em um serviço, o capital cria a crise e desarticula as instituiçóes para poder reorganizá-las tendo como objetivo o lucro. Para tanto, vale-se de conceitos como os de eficácia e eficiência, os quais são mensuráveis em termos de gestão e de desempenho (CHAUÍ, 1999).

Uma vez rearranjada em torno de interesses econômicos, uma organização passa a se diferenciar de uma instituição pela sua competição no mercado, mediante a dissolução de sua função social em meros números de desempenho constantes de relatórios que buscam garantir a sua correta operação: “[o] que importa não é aquela satisfação que, para os homens, se chama 'verdade', mas a 'operation', o procedimento eficaz" (ADORNO; HORKHEIMER, 1985, p. 20). Avaliada por índices de gestão e alheia à formação intelectual e moral, a organização se volta aos relatórios, à multiplicação de comissões, de mecanismos de controle e avaliação: "[o] problema da racionalidade das organizaçôes é que elas se tornam fins em si mesmos e não meios para cumprir os objetivos humanos" (CROCHÍK, 2008, p. 304). Não há como pensar em autonomia do sujeito para a pesquisa em um contexto de falta de liberdade, no qual as regras, enquanto limites do processo educacional, estão previamente postas e descompromissadas com a formação da moralidade.

Em se tratando do mundo administrado, "[o]s que dominam também são dominados pelo capital, não conseguem pensar para além dele, usam, no entanto, os mecanismos necessários para se manter no poder" (CROCHÍK, 2008, p. 302). A eliminação do sujeito autônomo, tanto na figura daquele que é dominado quanto daquele que domina, deixa o mundo à mercê da necessidade de lucro, custe o que custar. $\mathrm{O}$ mesmo se aplica à relação educacional, atingindo tanto a figura do educando quanto a do educador: 
No entanto o que vale para os educandos, também deve ser refletido em relação aos educadores. Também eles se vêem submetidos às exigências coativas do sistema educativo e às crescentes dissonâncias que este produz nos educandos, o que provoca um clima escolar dificilmente suportável, ou apenas suportável reduzindo friamente a práxis educativa ao cumprimento dos protocolos educativos burocraticamente fixados. Estaríamos, pois, diante da fórmula denunciada por Adorno: a eliminação do sujeito para assegurar sua autoconservaçáo (ZAMORA, 2008, p. 24-25).

Feitas essas considerações, é possível concluir que os espaços formativos estáo estruturados de uma forma que não favorece a formação da autonomia moral em pesquisa. Contudo, é importante esclarecer que não se está afirmando a completa impossibilidade da formação moral em instituiçóes educacionais, mesmo quando dominadas pela necessidade de lucro, pois a educabilidade do ser humano é uma questáo avessa a fórmulas e, apesar das dificuldades apontadas, existe um significativo número de docentes e pesquisadores que subverte esse estado de coisas.

\section{Questão filosófica}

Além de minar as possibilidades de emancipação do sujeito, a sociedade administrada esvazia as instâncias adequadas de reflexáo sobre a moralidade. A desvalorização da filosofia como campo do conhecimento fundamental à formação do ser humano faz parte do movimento do capital de redução da vida ao seu aspecto lucrativo, passando a interessar às instituiçôes de ensino táo somente o desenvolvimento de habilidades e competências desejadas pelas empresas. No Brasil, podemos citar como dois exemplos desse processo: a Lei no 13.415/17 (BRASIL, 2017), que retirou a obrigatoriedade de que a filosofia esteja presente no ensino médio enquanto disciplina, e o significativo crescimento das matrículas em cursos tecnológicos ${ }^{5}$, os quais contam com menor duração e têm currículos mais voltados ao mercado de trabalho. Nos exemplos citados, dificulta-se o desenvolvimento de um pensamento sistemático, metodologicamente organizado, sobre filosofia (mais ainda sobre ética) na medida em que retira, dos dois principais níveis educacionais, a reflexáo orientada por professores de filosofia sobre aspectos morais ${ }^{6}$.

Apesar da inestimável quantidade de obras escritas sobre o conceito de ética e sobre a sua apropriação ao longo da história da humanidade, identificar o âmago daquilo que verdadeiramente concerne à ética é mais simples do que normalmente se observa, desde que tal atividade seja conduzida de forma filosoficamente orientada. As divergências conceituais (sejam aparentes ou não) decorrem, na maioria das vezes, da tentativa infundada e injustificável de conferir elastici- 
dade artificial ao conceito de ética para que ele abranja mais do que aquilo que é intrinsecamente seu objeto. Essa maneira de se relacionar com o conceito parece cada vez mais recorrente em função de que, diante da falta de ética na sociedade, a proliferação da utilização do conceito, nas mais diversas instâncias e circunstâncias, é fenômeno crescente (até mesmo por sua evidente conveniência). Náo se observam debates públicos veiculados nos meios de comunicação sobre conhecimentos específicos, por exemplo, da Engenharia ou da Medicina, pois são respeitadas como áreas do conhecimento especializadas, fora da apropriação popular; no entanto, o mesmo cuidado não se observa ao tratar dos conceitos afetos à filosofia moral, os quais são de compartilhamento indispensável para a vida em sociedade.

Considerado a partir de sua dimensão filosófica, o conceito de ética é o mais fundamental ao ser humano e à vida no planeta. A partir disso, é possível perceber que não existem éticas ou diferentes éticas em diferentes campos do conhecimento, com diferentes abordagens; existe apenas um âmago que não pode ser afastado do conceito de ética. O centro do conceito de ética deve estar necessariamente comprometido com a manutenção da vida com dignidade, podendo ser aplicado de acordo com as singularidades do campo que se pretende. É fundamental a compreensão da necessidade de que o conceito de ética esteja comprometido com o mencionado cerne para o seu amadurecimento, fortalecimento e compartilhamento em todas as instâncias da sociedade. Nesse sentido:

[É]tica é, assim, o fundamento da condição humana que vive e medita sobre si, sobre seu lugar, sobre sua casa, seu oikos, suas relaçóes, seu mundo; ética é, neste sentido, essencialmente, uma questão eco-lógica. E, assim sendo, ética é o fundamento de todas as especificidades do viver, em suas mais complexas relaçóes e derivaçóes, da história das comunidades e da própria filosofia. $\mathrm{E}$, evidentemente, para o que aqui é relevante, emerge ao natural o primeiro postulado de nossa argumentação: a ética como fundamento da existência humana em todas as suas dimensões é igualmente o fundamento da possibilidade da pesquisa científica íntegra (SOUZA, 2012).

Por causa da falta de valorização da atividade filosófica para a compreensão da fundamentalidade do conceito de ética e a um ambiente social marcado pela injustiça (a mais grave forma de imoralidade), as questóes da filosofia moral são misturadas indevidamente com aspectos normativos com o apoio da própria sociedade em geral. A questão de ordem filosófica, nessa medida, também guarda relação com a apropriação indevida do conceito de ética pelo direito e pelas normatizações em geral. É o caso, por exemplo, da adoção da chamada ética principialista pela regulamentação da pesquisa nas Ciências Biomédicas (DINIZ, 2008). A própria possibilidade de adjetivação da ética já conduz a uma forçada ampliação daquilo que concerne à moral. Mais do que isso, o caráter normativo abstrato 
dessa perspectiva, fundada em quatro princípios fundamentais (autonomia, beneficência, não maleficência e justiça), mostra-se, desde a origem, incompatível com a realidade das pesquisas nas CHSSA. O princípio da autonomia, por exemplo, pressupóe a liberdade de escolha dos indivíduos envolvidos nas pesquisas, sua independência com relaçáo a condicionamentos sociais, o que, conforme argumentado, não se verifica na atividade científica, ainda menos nas CHSSA (DINIZ; GUILHEM, 2008).

A tentativa de apropriação desse conceito fundamental pelo direito tem como finalidade conferir à normatizaçáo um poder que ela não tem, qual seja, de instância definidora da ética. Nesse sentido, a própria pretensão de regulamentar a ética em pesquisa, tal qual indicada na Resolução CNS no 510/2016, apresenta-se como fonte de equívocos. Esse cuidado conceitual é fundamental no âmbito filosófico e deveria ser respeitado pela normatização, pois a falta de precisão no trato do conceito de ética é prejudicial em, pelo menos, duas instâncias: retira da ética uma clareza que lhe é fundamental para que seja um conceito compartilhado pela sociedade e reposiciona a possibilidade de conceituação da ética em um campo de forças no qual as Ciências Humanas e Sociais não têm condiçôes de participação efetiva.

Assim sendo, o alargamento artificial (normativo) do conceito de moralidade produz um falso problema aos pesquisadores das CHSSA: diante de um quadro de inadequação entre o modelo de regulação da pesquisa normatizado pelo CNS e a pesquisa em Educação, nas CHSSA, os pesquisadores das CHSSA, em geral, tendem a defender a necessidade de uma perspectiva ética própria ao tipo de pesquisa que realizam. Contudo, essa não é nem a melhor, do ponto de vista da defesa dos interesses pretendidos, nem a mais adequada, diante do conceito filosófico de ética, solução.

\section{A heteronomia normativa}

$\mathrm{Na}$ sociedade administrada não existem lacunas. A falta de instâncias que propiciem a formulação e o compartilhamento de conceitos morais é substituída pela atividade regulatória. Um levantamento realizado pelo Instituto Brasileiro de Planejamento e Tributação indicou que, desde a promulgação da Constituição Federal de 1988 (CF) até a divulgação da pesquisa, em 3 de julho de 2017, foram publicadas mais de 5,4 milhóes de leis; o que representava, em média, 769 novas normas por dia útil. Tal prática legislativa inflacionada encontra amparo na opinião da população em geral, a qual, carente de entendimento dos conceitos de filosofia moral e sem oportunidade adequada para a formação da autonomia necessária à moralidade, confia na criação e no endurecimento de leis como mecanismos eficazes de combate à crise ética, que há muito acomete o Brasil. Contudo, o caso brasileiro demonstra que o excesso de normas náo repercute em uma sociedade moralmente evoluída. 
Em sentido oposto ao excesso de normas, o raciocínio filosoficamente fundamentado indica que bastaria a observância dos cinco primeiros artigos da Constituição Federal, que tratam dos Princípios Fundamentais, para que se atingisse uma satisfatória garantia da ética em pesquisa. Do ponto de vista normativo, a CF é um instrumento suficiente para indicar os princípios éticos fundamentais para a vida em sociedade e, por consequência, nas pesquisas científicas. Nos referidos artigos está expressa a garantia da dignidade da pessoa humana, da livre manifestação do pensamento, da intimidade, que dispensa uma regulação tão abrangente (e ineficiente) como praticada pelo CNS. Isso não é à toa. Nada daquilo que é produzido socialmente é casuístico. Existe uma razão para isso e conhecer a razão pela qual o Brasil adotou um modelo demasiadamente regulamentador é essencial para fundamentar adequadamente a crítica.

$\mathrm{Na}$ origem dessa questão reside a disputa sobre o monopólio do processo de conhecimento para revelar a verdade. O Estado, desde sempre, buscou se afirmar como a instância de produção ou de validação da verdade. Contudo, a verdade produzida pelo Estado tem-se mostrado, ao longo da história, muito mais comprometida com interesses particulares do que com a desejável promoção da vida digna. Ora, considerando-se que o formato de empresa, cuja participação foi determinante no nascimento do direito moderno, baseia-se, internamente, sobretudo no cálculo, foi necessária a criação de um aparato jurídico cujo funcionamento pudesse ser calculado racionalmente de acordo com normas gerais, da mesma forma como se pode calcular o rendimento previsto de uma máquina. Weber estabelece essa relação entre Estado e burguesia como fundamental para o desenvolvimento do Estado moderno, afirmando que as empresas modernas só conseguiram se estabelecer

onde o juiz como num Estado burocrático com suas leis racionais, é mais ou menos um autômato regido por artigos, ao qual se enfiam goela abaixo as atas dos processos juntamente com os custos e honorários, e ele devolve a sentença junto com um arrazoado mais ou menos convincente, isto é, sua atividade é de toda forma, de um modo geral, previsível (WEBER, 1993, p. 44).

A ciência, tal qual o direito, é uma instância privilegiada de produção de verdades e, para o bom funcionamento do Estado burguês, as verdades científicas produzidas fora dos laboratórios de pesquisa privados devem ser previsíveis. Nesse processo de produção de verdades previsíveis, a domesticaçáo do cientista e a burocratização da atividade de pesquisa são medidas imperiosas para os interesses dominantes. A atividade científica exaustivamente normatizada é a garantia do controle sobre a produção de verdades. 
Basta adiantarmos inicialmente as seguintes considerações: tal como o ser humano, e exatamente como fruto do ser humano náo-neutro por definição, a ciência nada tem de neutra. $O$ mito da ciência neutra é muito conveniente àqueles que a manipulam, $e$ que, com ela, manipulam outros (SOUZA, 2012, grifo do autor).

A ausência de neutralidade da ciência decorre da já referida invasão dos interesses econômicos sobre a formação, os quais direcionam as atividades públicas apenas para o lucro. Nesse contexto de contaminação da ciência por interesses privados parece adequado que se exerça controle sobre a atividade científica. Contudo, o controle normativo, nascido de uma demanda legítima no contexto apresentado, extrapola a sua razão de ser (preocupação com a ética na pesquisa) e passa a representar o controle burocrático sobre a atividade do pesquisador. Por vezes, os próprios pesquisadores acabam vítimas dessa arapuca e passam a defender uma atividade normativa excessiva. Parece-nos que esse é o caso com relação à defesa de uma normatização específica para as pesquisas nas CHSSA. Não se trata de ignorar que a atual normatização, concebida com base no modelo da pesquisa biomédica, é inadequada para as pesquisas nas CHSSA, mas de perceber que o caminho a ser perseguido é o da desburocratização da pesquisa, com fortalecimento da liberdade e da autonomia dos pesquisadores, não o seu contrário.

O processo normativo da Resolução CNS no 510/2016 (BRASIL, 2016b) contribui para a análise do argumento acima construído, senão vejamos. De acordo com Mainardes (2017), a Associação Nacional de Pós-graduação e Pesquisa em Educação (ANPEd) promoveu as primeiras atividades para defender a necessidade de uma regulamentação própria para as pesquisas em Educação em 2007, por meio de uma Comissão de Ética em Pesquisa. Contudo, as atividades de referida comissão foram descontinuadas por falta de apoio. Em 2012, foi aprovada, em assembleia geral da ANPEd, uma moção à Comissão Nacional de Ética em Pesquisa (CONEP), solicitando a efetivação de uma normativa complementar para as Ciências Humanas e Sociais, anunciada na Resolução CNS no 466/2012 (BRASIL, 2012) ${ }^{7}$.

Em 2013, a ANPEd passou a integrar, com 28 associaçóes profissionais das CHSSA, um Grupo de Trabalho (GT) no âmbito da CONEP, que teve como objetivo elaborar o projeto de complementação dessa normativa (MAINARDES, 2017). Em que pesem o empenho e a firme atuação de referido GT, existe consenso na área das CHSSA no sentido de que a Resoluçáo CNS no 510/2016 ficou bastante limitada com relação às expectativas de uma normatização mais adequada à área ${ }^{8}$. Mais do que isso: após a publicação da Resolução CNS no 510/2016, o GT das CHSSA foi dissolvido e a representação da área vem sendo sistematicamente impedida de participar das atividades necessárias de regulamentação de dispositivos normativos que deveriam, em alguma medida, contemplar as suas especificidades. Como prova disso é possível mencionar o abaixo-assinado organi- 
zado pelo Fórum das Ciências Humanas, Sociais e Sociais Aplicadas (FCHSSA), exigindo a participação paritária da área nas atividades de regulamentação da normativa, com especial prioridade na elaboração de uma resolução regulamentando os riscos envolvidos nas pesquisas nas CHSSA, previstos de forma genérica na Resolução CNS no 510/2016, e com relação à adequação da Plataforma Brasil.

Esse caso exemplifica o argumento de que o processo normativo, além das limitaçóes com relação ao desenvolvimento da autonomia moral do pesquisador, tende a seguir um caminho diverso daquele previsto na origem (via de regra, legítimo). Os pesquisadores, reais conhecedores da demanda, iniciam o processo, mas não têm controle sobre a sua conclusão; acabam gerando, involuntariamente, mais burocracia sobre a pesquisa. Outro ponto a ser considerado é o campo de disputa de forças desiguais nas áreas que são objeto de normatização, fato que acaba favorecendo invasōes normativas de esferas hegemônicas sobre esferas menos expressivas política e economicamente.

Para além do casuísmo da pesquisa em educação, ou da própria regulação da pesquisa, evidencia-se um modelo de controle normativo no qual os próprios interessados são o motor para uma crescente normatização e consequente controle da vida em sociedade: "incontáveis indivíduos — e pode-se mesmo dizer: a maioria avassaladora dos homens - agem seriamente de modo contrário a seus interesses racionais" (ADORNO, 2008, p. 274). A burocratização da atividade científica, além de não ser capaz de efetivamente garantir que a integralidade da pesquisa observe preceitos éticos (por uma evidente impossibilidade do formal diante do real), acaba obstaculizando o andamento de projetos adequadamente concebidos, mas que não se enquadram no modelo normativo (SIQUELLI, 2017). Isso se verifica, por exemplo, nas dificuldades impostas pela regulação da pesquisa ao documentário etnográfico enquanto instrumento científico sério, capaz de evidenciar verdades.

Assumir que o documentário etnográfico é uma peça acadêmica resultante de pesquisa é também demarcar sua fronteira com a liberdade criativa da ficção. A despeito de todas as críticas pós-modernas à etnografia, o documentário etnográfico está imerso em compromissos modernos da pesquisa científica, tais como a veracidade dos dados, o compromisso com a objetividade e, especialmente, o cumprimento de procedimentos metodológicos de coleta dos dados durante o trabalho de campo (DINIZ, 2008).

Na mesma linha, é possível pensar sobre a exigência do Termo de Consentimento e Esclarecido (TCLE), constante da Resolução CNS no 466/2012. Há casos em que a postura ética em pesquisa pode ser definida pela manutençáo do anonimato dos participantes da pesquisa ou, dependendo do caso, pela revelação do nome dos participantes da pesquisa ${ }^{9}$. Em determinadas situações, espe- 
cialmente nas ciências médicas, a manutenção do anonimato dos participantes da pesquisa pode ser entendida como uma medida fundamental para que se evite a estigmatização e o preconceito, especialmente diante de participantes em condiçóes de vulnerabilidade. Por outro lado, em uma pesquisa no campo da memória coletiva, envolvendo participantes que foram vítimas de violência no período da ditadura militar, por exemplo, a revelação dos nomes pode se apresentar como fundamental medida de justiça e reparação histórica. Ambas as posturas (revelar ou não) podem ser consideradas comprometidas com a ética, desde que esta esteja corretamente entendida como o respeito pela dignidade da vida.

Assim sendo, as particularidades das CHSSA evidenciam que a regulação da pesquisa tal qual exercida pelo CNS é um modelo insustentável (pois jamais serão contempladas pela normatização todas as possibilidades de pesquisa) e ineficiente (pois ela se ocupa apenas do formal, tendo como consequência nefasta, além de não garantir a ética em pesquisa, burocratizar e tornar lento o processo de pesquisa nas CHSSA).

\section{Considerações finais}

Diante dos argumentos, as três instâncias referidas (formativa, filosófica e normativa) são de articulação conjunta necessária para pensar a possibilidade de autonomia ética em pesquisa. Mesmo que reconhecida a interdependência inicial das três esferas, a possibilidade de autonomia ética reside fundamentalmente em um processo educacional pensado desde a sua origem para o exercício da autonomia e viabilizado por condiçōes sociais que tornem o referido processo, no mínimo, suportável com dignidade.

Contudo, em sentido contrário, tem-se presenciado o avanço da regulamentação externa das condutas (heteronomia) e a desvalorização do espaço e das condições para exercício da autonomia ética do sujeito (por consequência, do pesquisador). Nesse sentido, os graves contingenciamentos de verbas praticados contra o ensino gratuito, em especial contra a universidade pública, em contraposição aos sempre crescentes gastos com o legislativo e o judiciário, dão conta de uma opção política mais comprometida com o controle sobre a atividade científica do que com a promoção da autonomia ética dos pesquisadores. Tal constatação é de vital importância para que as CHSSA reúnam esforços contra aquilo que verdadeiramente coloca em risco a autonomia da pesquisa na área, deixando de lado disputas menores por identidade de campos de pesquisa, especificidades, adjetivaçôes impróprias ao conceito de ética etc. Faz-se imperioso compreender que a disputa não deve ser por mais normas, nem por normas mais específicas, mas sim pelo compartilhamento social do que é fundamental ao conceito de ética e pela criação das condiçóes sociais necessárias para o desenvolvimento da autonomia ética. 
Importante reiterar que não se está afirmando que a regulação não seja necessária, contudo é fundamental compreender os limites de possibilidade da normatização, enquanto mecanismo incapaz (na medida em que é impróprio) para garantir a ética em pesquisa. O direito, manifestado especialmente pela normatização (codificação, regulação etc.), é necessário; contudo, ele não é nem mesmo se confunde com a ética. É desejável que a legislação seja cumprida para que a vida em sociedade seja organizada; entretanto, a ética é uma qualidade humana que não está acessível por meio da regulação externa das condutas.

A partir disso, o grande prejuízo imposto ao pesquisador (sobretudo à pesquisa) pelo atual modelo burocratizado está em não fomentar a autonomia científica, nem a verdadeira autonomia ética em pesquisa. É necessário integrar os pesquisadores como partes fundamentais de um modelo a ser aplicado em todos os níveis da sociedade para a formação em pesquisa pautada pela autonomia ética desde a educação básica, e com o devido reconhecimento social aos pesquisadores das CHSSA, especialmente considerando as condiçôes materiais para o exercício da pesquisa. Naturalmente, essa medida, para ser efetiva, deveria ser precedida de uma maior autonomia das instituiçóes de pesquisa e de sua atividade precípua com relação a interesses econômicos. Além do que, para finalizar, o comprometimento moral que marca as pesquisas nas CHSSA ao longo da história do Brasil está longe de ser merecedor de tamanha preocupação normativa, tampouco as pesquisas nas CHSSA envolvem riscos semelhantes às ciências biomédicas, que servem de paradigma à regulação.

\section{Notas}

1. "Adorno desenvolveu o conceito de sociedade administrada para mostrar que, na lógica do capitalismo, tudo se reduz a uma administração eficiente e lucrativa, incluída a vida humana. As decisôes dos sujeitos, as deliberaçôes aparentemente livres, estấo perpassadas por mediaçôes objetivantes que conseguem induzir e administrar a vida dos sujeitos" (RUIZ, 2012).

2. Com relação à escolha da palavra emancipação, Vilela (2007, p. 235-236) adverte: "Parece-nos fundamental esclarecer o termo alemão, utilizado por ele [Adorno], para indicar seu pensamento sobre a escola e a Educação, pois o vocábulo português 'emancipação' não revela o sentido pleno tomado pelo teórico. Ao escolher a palavra, Adorno procurou, com ela, revelar a essência do seu pensamento: a educação e o processo social de dominação apresentam uma mesma raiz. Mund significa 'boca'. Mündigkeit significa a capacidade de falar pela própria boca, falar por si mesmo; mas, para essa condição, o sujeito precisa ser capaz de pensar por si mesmo. Entretanto, o processo social de dominação retirou do homem a capacidade de pensar por conta própria, retirou dele a capacidade de autonomia das suas açóes, de falar e de agir por si mesmo".

3. Nesse sentido, embora seja relevante a questão da formação do pesquisador em sua relação com a ética, o objetivo do presente artigo é de tensionar as possibilidades de falar-se em uma autêntica formação no âmbito de instituiçôes cada vez mais burocratizadas e organizadas de acordo com inte- 
resses econômicos, restringindo o campo da autonomia do sujeito, na linha da filosofia adorniana: "[A] psicologia social indica a relação entre o indivíduo e a sociedade; deve ter a sua especificidade que não coincida nem com a psicologia, nem com a sociologia. Adorno entende essa relação de maneira a não restringir esse objeto a uma mera 'interação simétrica' entre dois fenômenos. Primeiro, porque critica a sociologia pensada sem indivíduos e a psicologia voltada unicamente ao seu objeto, por desconhecer que esse se desenvolve socialmente e que é a sociedade e a cultura que lhe permitem se constituir como indivíduo; segundo, porque essa relação é histórica e, assim, a possibilidade do indivíduo ser mais ou menos diferenciado depende da configuração social e de sua necessidade de reprodução (não é casual que o autor enfatize que a sociedade produz os homens que necessita para se manter tal como é); terceiro, porque a sociedade não determina externamente a formação do indivíduo, mas de forma imanente; e por fim, porque na atualidade a sociedade tem primazia acerca da determinação do comportamento individual” (CROCHÍK, 2008, p. 297-298).

4. Existem diversas interpretaçóes (e muitas críticas) sobre a eventual incorporação, por parte de Adorno, da análise realizada por Pollock (no sentido da transformação do capitalismo em um capitalismo estatal, o que repercutiria numa dominação mais política do que econômica). Contudo, essa não parece ser a posição mais acertada. Compreendemos, junto com Pedroso (2009; 2013), Zuidervaart (2011) e Fleck (2015), que Adorno rejeita a análise de Pollock e mantém a sua crítica centrada no capitalismo, nas formas econômicas de dominaçáo sobre o indivíduo. Nesse sentido, ver: Fleck (2015).

5. Segundo o Censo da Educação Superior do MEC de 2016, "de 2006 a 2016, as matrículas nos cursos tecnológicos quase triplicaram (190,3\% de aumento)” (BRASIL, 2016a).

6. É preciso considerar que a condução da reflexão ética é tarefa árdua, que depende da formação adequada e de condiçóes de trabalho dignas para os professores de filosofia, além das demais ressalvas feitas por Adorno em 1961, no texto "A filosofia e os professores" (ADORNO, 1995).

7. Referida normativa substituiu a Resolução CNS no 196/96, que igualava todas as áreas do conhecimento em um controle concebido com base nas pesquisas em saúde, de caráter clínico e experimental, a partir do denominado Sistema CEP/CONEP, integrado por Comitês de Ética em Pesquisa (CEP) e pela CONEP, regulado por normativas do Conselho Nacional de Saúde (BRASIL, 1996). As dificuldades e os conflitos derivados das avaliaçóes das pesquisas das CHSSA nesse âmbito e os confrontos com as associaçóes profissionais desses campos do conhecimento levaram a incluir na segunda normativa o seguinte artigo: "As especificidades éticas das pesquisas nas ciências sociais e humanas e de outras que se utilizam de metodologias próprias dessas áreas serão contempladas em resolução complementar, dadas suas particularidades” (BRASIL, 2012).

8. Uma análise detalhada do conturbado processo de aprovaçáo dessa normativa pode ser consultada no dossiê da Revista Brasileira de Sociologia, com vários artigos de autoria de representantes do mencionado GT, entre outros: Duarte (2015), Sarti (2015), Edler (2015), Santos, Jeolás (2015), Sobottka (2015) e Zaluar (2015).

9. Essas questôes e outras referidas às discussóes sobre regulação da ética na pesquisa foram amplamente trabalhadas nas produçóes das CHSSA; para maiores detalhes, ver: de la Fare, Machado e Carvalho (2014) e de la Fare, Carvalho e Pereira (2017). 


\section{Referências}

ADORNO, T. W. Minima moralia. São Paulo: Ática, 1993.

ADORNO, T. W. Educação e emancipação. Rio de Janeiro: Paz e Terra, 1995.

ADORNO, T. W. Introduçáo à sociologia. São Paulo: Unesp, 2008.

ADORNO, T. W.; HORKHEIMER, M. Dialética do Esclarecimento. Rio de Janeiro: Jorge Zahar, 1985.

BRASIL. Instituto Nacional de Estudos e Pesquisas Educacionais Anísio Teixeira (INEP). Censo da educaçáo superior, 2016. Brasília: INEP, 2016a. Disponível em: <www.inep. gov.br>. Acesso em: 2 fev. 2018.

BRASIL. Resoluçáo no 196/1996: diretrizes e normas regulamentadoras de pesquisas envolvendo seres humanos. Brasília: Ministério da Saúde/Conselho Nacional da Saúde, 1996.

BRASIL. Resoluçáo no 466/2012: diretrizes e normas regulamentadoras de pesquisas envolvendo seres humanos. Brasília: Ministério da Saúde/Conselho Nacional de Saúde, 2012.

BRASIL. Resolução no 510/2016: ética em pesquisa em Ciências Humanas e Sociais. Brasília: Ministério da Saúde/Conselho Nacional de Saúde, 2016b.

BRASIL. Lei no 13.415, de 17 de fevereiro de 2017. Altera a Lei no 9.394, de 20 de dezembro de 1996, e dá outras providências. Diário Oficial da Uniáo, Brasília, 17 fev. 2017.

CHAUÍ, M. A universidade operacional. Avaliação, v. 4, n. 3, suplem. 1, p. 3-8, 1999.

CROCHÍK, J. L. T. W. Adorno e a psicologia social. Psicologia \& Sociedade, v. 20, n. 2 , p. 297-305, 2008.

DE LA FARE, M.; CARVALHO, I. C. M.; PEREIRA, M. V. Ética e pesquisa em educação: entre a regulação e a potencialidade reflexiva da formação. Educaçáo, Porto Alegre, v. 40, n. 2, p. 192-202, maio-ago. 2017. http://dx.doi.org/10.15448/1981-2582.2017.2.27603

DE LA FARE, M.; MACHADO, F. V.; CARVALHO, I. C. M. Breve revisão sobre regulação da ética em pesquisa: subsídios para pensar a pesquisa em educação. Práxis Educativa, Ponta Grossa, v. 9, n. 1, p. 247-283, jan./jun. 2014. http://dx.doi.org/10.5212/ PraxEduc.v.9i1.0012

DINIZ, D. Ética na pesquisa em ciências humanas: novos desafios. Ciência \& Saúde Coletiva, v. 13, n. 2, p. 417-426, 2008. Disponível em: <http://www.redalyc.org/ pdf/630/63013213.pdf >. Acesso em: 28 mar. 2017.

DINIZ, D.; GUILHEM, D. O que é bioética. São Paulo: Brasiliense, 2008.

DUARTE, F. C.; NACLE, I. C. C. Subsidiariedade: a evolução do princípio constitucional limitador da interferência estatal. Seqüência, n. 68, p. 91-107, jun. 2014. Disponível em: <http://www.scielo.br/pdf/seq/n68/05.pdf > . Acesso em: 15 jan. 2018. http://dx.doi. org/10.5007/2177-7055.2013v35n68p91 
DUARTE, L. F. D. A ética em pesquisa nas Ciências Humanas e o imperialismo bioético no Brasil. Revista Brasileira de Sociologia, v. 3, n. 5, p. 31-52, jan./jun. 2015. http://dx.doi.org/10.20336/rbs.90

EDLER, F. A Húbris Bioética: rumo a uma polícia epistemológica? Revista Brasileira de Sociologia, Brasília, v. 3, n. 5, p. 95-113, jan./jun. 2015. Disponível em: <http://www. sbsociologia.com.br/revista/index.php/RBS/article/view/95>. Acesso em: 20 out. 2016. http://dx.doi.org/10.20336/rbs.95

FLECK, A. O. Theodor W. Adorno: um crítico da era dourada do capitalismo. 2015. 202 f. Tese (Doutorado em Filosofia) - Centro de Filosofia e Ciências Humanas. Universidade Federal de Santa Catarina, Florianópolis, 2015.

FRANKFURT, H. G. Sobre falar merda. Rio de Janeiro: Intrínseca, 2005.

GOERGEN, P. Educação, ética e mercado. 2015. Disponível em: <http://www2.ufopa. edu.br/ufopa/arquivo/divdocs/2015/pedro-goergen-educacao-etica-mercado/view $>$. Acesso em: 3 mar. 2016.

GOMES, L. R. Teoria crítica da educação: experiências atuais de pesquisa no Brasil e na Alemanha. Comunicaçóes, Piracicaba, v. 22, n. 3, p. 145-154, 2015. http://dx.doi. org/10.15600/2238-121X/comunicacoes.v22n3p145-154

GOMES, L. R. Frieza burguesa e educaçáo: a frieza como mal-estar moral da cultura burguesa na educação. Campinas: Autores Associados, 2014.

MAINARDES, J. A ética na pesquisa em educação: panorama e desafios pós-Resolução CNS no 510/2016. Educaçáo, Porto Alegre, v. 40, n. 2, p. 160-173, maio-ago. 2017. http://dx.doi.org/10.15448/1981-2582.2017.2.26878

OLIVEIRA, L. A. Inflaçáo normativa: excesso ou exceção. 2009. Dissertação (Mestrado em Direito) - Universidade Federal de Santa Catarina, Florianópolis, 2009. Disponível em: <https://repositorio.ufsc.br/handle/123456789/92634>. Acesso em: 2 fev. 2018.

PEDROSO, G. Capitalismo de Estado ou Capitalismo Tardio. In: CARVALHO, M.; FIGUEIREDO, V. Filosofia alemá: de Marx a Nietzsche. São Paulo: ANPOF, 2013. p. 99-106.

PEDROSO, G. Entre o capitalismo de Estado e o Behemoth: o Instituto de Pesquisa Social e o fenômeno do fascismo. Cadernos de Ética e Filosofia Política, v. 15, p. 151-179, 2009.

RUIZ, C. B. Genealogia da biopolítica. Legitimações naturalistas e filosofia crítica. Revista IHU On-Line, São Leopoldo, n. 386, mar. 2012. Disponível em: <http://www. ihuonline.unisinos.br/index.php?option $=$ com content $\& v i e w=$ article $\& i d=4308>$. Acesso em: 12 ago. 2018.

SANTOS, L. A. C.; JEOLÁS, L. Uma Comissão Nacional de Ética na Pesquisa, as Ciências Biomédicas e as Ciências Humanas: trespassing à brasileira. Revista Brasileira de Sociologia, Brasília, v. 3, n. 5, p. 239-259, jan./jun. 2015.http://dx.doi.org/10.20336/rbs.102

SARTI, C. A ética em pesquisa transfigurada em campo de poder: notas sobre o sistema CEP/Conep. Revista Brasileira de Sociologia, Porto Alegre, v. 3, n. 5, p. 79-96, jan./jun. 2015. http://dx.doi.org/10.20336/rbs. 94 
SIQUELLI, S. A. O que mudou para as pesquisas em educação? Possibilidades de parâmetros éticos e políticos. In: SANTOS, L. H. S.; KARNOPP, L. B. (orgs.), Ética e pesquisa em educação: questóes e proposiçóes às ciências humanas e sociais. Porto Alegre: Editora da UFRGS, 2017.

SOBOTTKA, E. A. Regulamentação, ética e controle social na pesquisa em Ciências Humanas. Revista Brasileira de Sociologia, Brasília, v. 3, n. 5, p. 51-77, jan./jun. 2015. http://dx.doi.org/10.20336/rbs.93

SOUZA, R. T. Integridade ética e científica da pesquisa. 2012. Disponível em: $<\underline{\text { http:// }}$

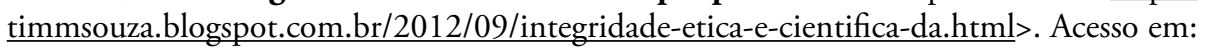
30 mar. 2017.

SOUZA, R. T. Sobre a construçáo do sentido. São Paulo: Perspectiva, 2003.

VILELA, R. A. T. Críticas e possibilidades da educação e da escola na contemporaneidade: liçóes de Theodor Adorno para o currículo. Educaçáo em Revista, Belo Horizonte, v. 45, p. 223-248. jun. 2007. http://dx.doi.org/10.1590/S0102-46982007000100012

ZALUAR, A. Ética na pesquisa social: novos impasses burocráticos e paroquiais. Brasília. Revista Brasileira de Sociologia, v. 3, n. 5, p. 133-157, jan./jun. 2015. http://dx.doi. org/10.20336/rbs.97

ZAMORA, J. A. Educação depois de Auschwitz. In: MOREIRA, A. S.; PUCCI, B.; ZAMORA, J. A. Adorno: Educaçáo y Religiáo. Goiânia: Editora UCG, 2008. p. 11-27.

ZUIDERVAART, L. Theodor W. Adorno. In: ZALTA, E. (org.). The Stanford Encyclopedia of Philosophy. 2011. Disponível em: <http://plato.stanford.edu/archives/ win2011/entries/adorno >. Acesso em: 5 ago. 2018.

WEBER, M. Parlamentarismo e governo na Alemanha reordenada. Petrópolis: Vozes, 1993.

\section{SOBRE OS AUTORES}

Pedro Savi Neto é pós-doutorando pelo Programa de Pós-graduação em Educação da Escola de Humanidades da Pontifícia Universidade Católica do Rio Grande do Sul (PUC-RS). Professor colaborador também do Programa de Pós-graduação em Educação da Escola de Humanidades da PUC-RS.

Mónica de La Fare é professora do Programa de Pós-graduação em Educação da Escola de Humanidades da Pontifícia Universidade Católica do Rio Grande do Sul (PUC-RS).

Recebido em 8 de fevereiro de 2018.

Aceito em 5 de outubro de 2018. 